\title{
THERMAL AND HYDRAULIC PERFORMANCE OF A NOVEL EVAPORATOR COIL FOR REFRIGERATION SYSTEMS
}

\author{
Hossam M. Elkady, Mostafa H. Sharqawy* \\ School of Engineering, University of Guelph \\ Guelph, ON N1G 2W1, Canada \\ *melsharq@uoguelph.ca
}

Sameh M. I. Saad, Kazi K. Ahmed

Betterfrost Technologies Inc.

Toronto, ON M5G 1L7, Canada

$\begin{array}{lll}Q & \text { cooling capacity } & \text { W } \\ r & \text { coil radius } & \mathrm{m} \\ \rho & \text { density } & \mathrm{kg} \mathrm{m}^{-3} \\ t & \text { thickness of fin } & \mathrm{m} \\ T & \text { temperature } & { }^{\circ} \mathrm{C} \\ V & \text { velocity } & \mathrm{m} \mathrm{s}^{-1} \\ \dot{V} & \text { volumetric flow rate } & \mathrm{m}^{3} \mathrm{~s}^{-1} \\ w & \text { depth of fin } & \mathrm{m}\end{array}$

Subscripts

$\begin{array}{ll}\text { in } & \text { inlet } \\ \text { out } & \text { outlet } \\ w & \text { water }\end{array}$

\section{INTRODUCTION}

Evaporator coils are an essential component to any refrigeration equipment because it is where cooling takes place. Most commonly used evaporator coil includes fins to increase the surface area, thereby increasing the heat transfer. One frequent problem with evaporators in commercial refrigeration applications is frosting on the coils. As the frost builds up on the evaporator, the pressure drop across the evaporator increases, resulting in a decrease of volumetric air flow across the evaporator, and subsequent loss of heat transfer. Currently, to mitigate this, a time consuming and not cost efficient defrost cycle must take place.

Pulse electro-thermal de-icing (PETD) is a method of ice removal and prevention that uses short pulses of electricity applied directly to an ice-material interface [1]. It takes $1 \mathrm{~ms}$ to $5 \mathrm{~s}$ long heat pulses to heat a minimal layer of interfacial ice causing the ice to slide off on the resulting thin water film. Using this technology with the current design of the fins on the evaporator will not be effective due to the small spacing between the fins and low electrical resistance of the coil. However, pairing it with the Betterfrost Technologies helical finless coil that offers a pitch great enough to allow ice to slide off and the right electrical resistance, unlocks incredible potential in commercial cooling applications as an energy and cost saving mechanism. 
The most commonly used form of finned tube heat exchangers is equipped with plain fins due to its structural simplicity along with its versatility in applications where lowpressure drop is required [2]. Other forms of enhanced surfaces such as wavy, offset strip and louvered, offer heat transfer enhancement due to the boundary layer separation as well as the repeated growth and wake destruction of the boundary layer. However, finned-tube heat exchanger efficiencies can significantly decrease at certain ambient conditions due to accumulation of frost on the fins [3].

This paper presents an experimental study which focuses on the thermal and hydraulic performance of a helical-spiral finless coil and comparing it with a finned-tube heat exchanger. The experimental data helps understanding the thermal and hydraulic boundaries of both heat exchangers which are correlated to the cooling capacity and air pressure drop variations with the air flow rate.

\section{Experimental Setup AND Procedure}

\section{A. Experimental Setup}

Schematic of the finned-tube evaporator and finless helical-spiral evaporator coils are shown in Figures 1 and 2 respectively. The finned-tube coil has a $3 / 8$ " copper pipes and $0.25 \mathrm{~mm}$ thickness aluminum fins, while the finless helicalspiral coil consists of bare stainless-steel pipes of $3 / 8$ " diameter. The other geometrical parameters for both evaporator coils are given in Table 1 and 2 for the finned-tube and finless coils respectively.
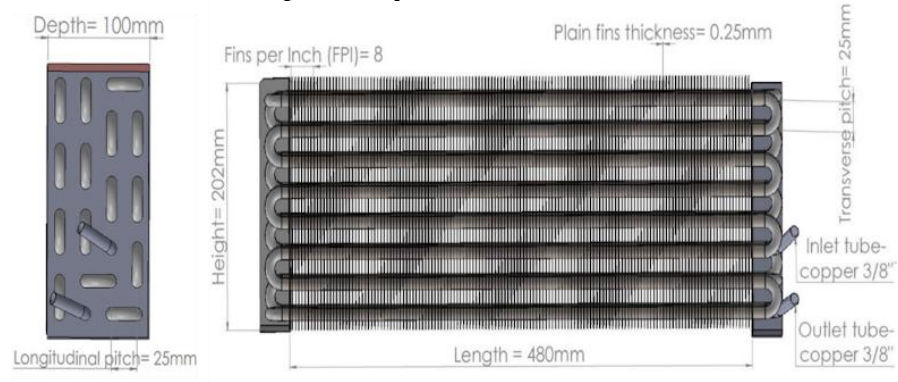

Figure 1 Schematic of the finned-tube evaporative coil
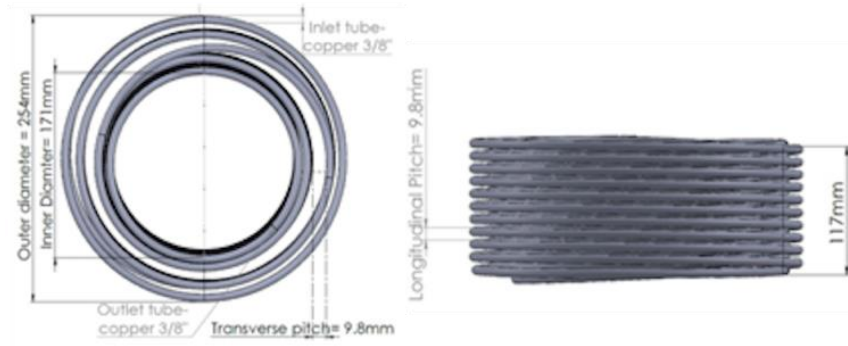

Figure 2 Schematic of the spiral-helical finless evaporative coil

A schematic of the evaporator coil test unit used in this study is shown in Figure 3. The test section is a plexiglass acrylic duct with cross-sectional dimensions of 14 "x 24 ". The setup is used to measure the cooling capacity and the air pressure drop across both coils with air axially entering the duct through a bell mouth entrance equipped with flow straighteners, passing through the coils and discharged axially.

Table 1 Geometric parameters for finned-tube coil

\begin{tabular}{ll}
\hline Geometry parameter & Value \\
\hline Pipe outer diameter, $D_{o}$ & $9.78 \mathrm{~mm}$ \\
Pipe Length, $L_{\text {pipe }}$ & $480 \mathrm{~mm}$ \\
Number of pipes, $N_{\text {pipes }}$ & 32 \\
Fin height, $h$ & $202 \mathrm{~mm}$ \\
Number of fins, $N_{\text {fins }}$ & 150 \\
Fin thickness, $t$ & $0.25 \mathrm{~mm}$ \\
Fin width, $w$ & $100 \mathrm{~mm}$ \\
\hline
\end{tabular}

Table 2 Geometric parameters for helical finless coil

\begin{tabular}{ll}
\hline Geometry parameter & Value \\
\hline Pipe outer diameter, $D_{o}$ & $9.78 \mathrm{~mm}$ \\
Number of coils & 2 \\
Number of turns, $N_{\text {turns }}$ & 32 \\
Pitch, $p$ & $9.8 \mathrm{~mm}$ \\
Average coil radius, $r$ & $127 \mathrm{~mm}$ \\
\hline
\end{tabular}

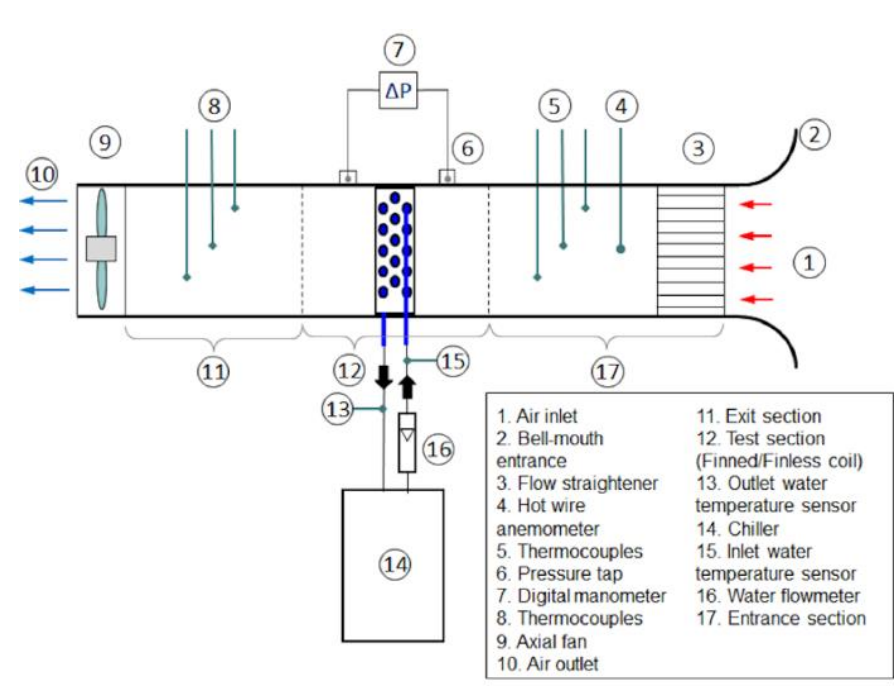

Figure 3 Schematic diagram of experimental apparatus

Two finless helical-spiral coils are installed next to each other to get the same face (flow) area of the finned-tube coil and to measure and compare their cooling capacity as well as pressure drop. An axial flow fan with variable speed is installed at the duct exit so that air at room temperature is blown through the coils of the heat exchanger.

\section{B. Instrumentation}

Temperature and pressure drop instruments are installed in accordance to the ASHRAE Standard 33-78 [4]. Instruments are installed to measure the temperatures and flow rates of both air and water streams. Three K-type thermocouples are installed at the inlet and outlet of the air and water streams to measure the dry bulb and water temperatures. Water flow rate is measured using a glass tube 
rotameter (Omega FL-50003A-V) of $\pm 5.0 \%$ accuracy and a range of $1-7 \mathrm{l} / \mathrm{min}$. The air velocity is measured using a digital vane anemometer (Omega HHF11A) of $\pm 5 \%$ accuracy and a hot wire anemometer (HHF-SD1) of $\pm 0.8{ }^{\circ} \mathrm{C}$ accuracy. A handheld temperature data logger (Omega HH374) is used to display and record the measured temperatures from the thermocouples. Finally, the coil pressure drop is measured using a handheld differential manometer (OMEGA HHP886U).

\section{Experimental Procedure}

Water inlet temperature is adjusted throughout the testing phase to ensure at least a Logarithmic Mean Temperature Difference (LMTD) of 8 is achieved. For all runs, the water flow rate and water inlet temperature were kept at $2.5 \mathrm{l} / \mathrm{min}$ and $12 \pm 0.1^{\circ} \mathrm{C}$ respectively. For each run, the fan was adjusted to draw ambient air towards the coil at different volumetric flow rates. The experiment was carried out by circulating cold water in the coil to cool the ambient air being drawn by the axial fan. All temperatures were recorded manually after running the system for $15-20$ minutes to ensure that it reached steady state condition. All measurements are taken at room condition which has an air temperature of $22^{\circ} \mathrm{C} \pm 1^{\circ} \mathrm{C}$ and atmospheric pressure which is assumed to be 101.325 $\mathrm{kPa}$.

\section{Mathermatical ANalysis}

The measured variables for both coils include the inlet and outlet air temperatures of both air and water, the inlet air speed, and water flow rate. The following equation was used to calculate the air flow rate in cubic feet per minute (CFM).

$$
\dot{V}=2118.8 V_{\text {in }} A_{\text {in }}
$$

where $V_{\text {in }}, \mathrm{A}_{\text {in }}$, and 2118.88 are the inlet air velocity, entrance cross-sectional area of the air, and a conversion factor from $\mathrm{m}^{3} / \mathrm{s}$ to CFM respectively. Water mass flow rate in the coil pipes is calculated using the following equation.

$$
m_{w}=V_{\text {in }} \rho_{w}
$$

The cooling capacity of the coil is calculated using as following equation.

$$
Q=m_{w} c_{w}\left(T_{w, o u t}-T_{w, \text { in }}\right)
$$

The total surface area of the finned-tube coil is calculated using the following equations.

$$
\begin{aligned}
& A_{\text {fin }}=N_{\text {fins }} *\left(2 h * w-N_{\text {pipes }} \frac{\pi}{4} D_{o}^{2}\right) \\
& A_{\text {unfin }}=N_{\text {pipes }} \pi D_{o}\left(L_{\text {pipe }}-N_{\text {fins }} * t\right) \\
& A_{\text {total }}=A_{\text {fin }}+A_{\text {unfin }}=6.134 \mathrm{~m}^{2}
\end{aligned}
$$

The surface area of the finless coil is calculated using the following equations.

$$
\begin{gathered}
L_{\text {coil }}=N_{\text {turns }} * \sqrt{(2 \pi r)^{2}+p^{2}} \\
A_{\text {helical }}=2 * \pi D_{o} L_{\text {coil }}=1.569 \mathrm{~m}^{2}
\end{gathered}
$$

\section{RESUlTS AND DISUCSSION}

The experimental results showed that the cooling capacity and coil air pressure drop increases with the air flow rate. The coil performance was evaluated by calculating the cooling capacity and pressure drop of both the finned and finless coils for various air and water flow configurations. The most desirable setup and configuration that yielded the highest cooling capacity was found to be a mixed axial-radial (MAR) air flow configuration with a bell-mouth entrance (B) and a cross-counter (CC) water flow configuration. The same configuration was tested for both the finned-tube heat exchanger (FINHX) and the finless double helical coils with and without a separator between the two coils to avoid the air interreference effect.

\section{A. Cooling Capacity}

In Figure 4, the cooling capacity per coil total surface area is shown in Watts per meter squared $\left(\mathrm{W} / \mathrm{m}^{2}\right)$ and plotted against the air flow rate in cubic feet per meter (CFM). The water flow rate value was maintained constant at $2.5 \mathrm{l} / \mathrm{min}$ for all runs. Data were taken at low and high air flow rates of about 400 and $600 \mathrm{CFM}$. Since the air pressure drop of every coil is different, the flow rate of the suction fan was different. The logarithmic mean temperature difference (LMTD) was almost constant at $8{ }^{\circ} \mathrm{C}$.

The data shows a higher cooling capacity per surface area for the finless helical-spiral coil compared with the finnedtube one at both air flow rates. This is mainly due to higher convection heat transfer coefficient since LMTD and water flow rate are fixed. The curvature of finless helical-spiral coil induces a secondary flow which provide greater turbulences that leads to higher heat transfer coefficient [5] contributing to a better cooling capacity per surface area. While the surface area of the finned-tube is almost four times greater than the finless helical-spiral coil, the cooling capacity per surface area for the finless coil is more than twice that of the finned-tube. In addition, separating the double coils has almost no significant effect on the cooling capacity compared with them unseparated as shown in Figure 4.

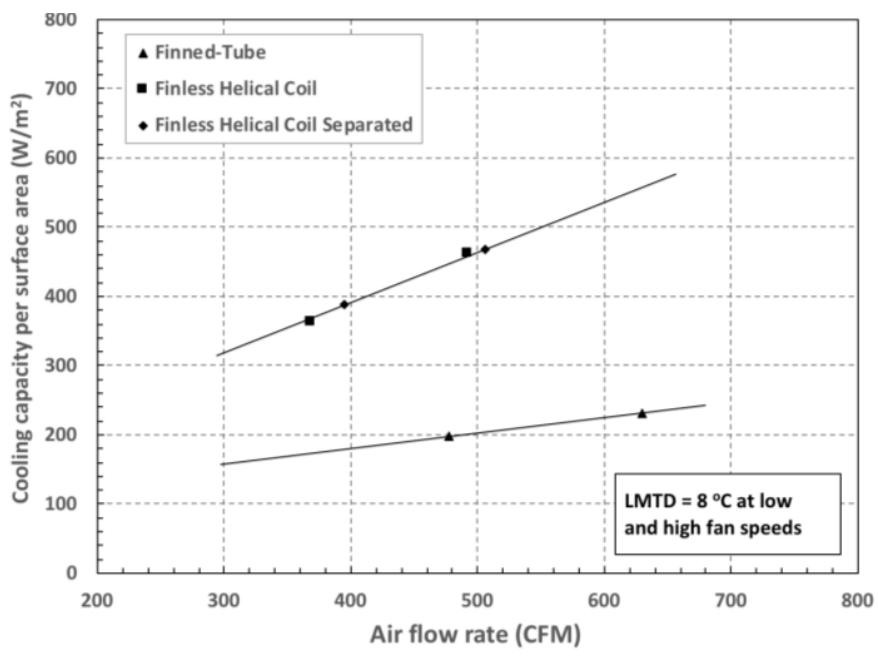

Figure 4 Cooling capacity per surface area of finned-tube and helicalspiral evaporative coil for bell-mouth air flow configuration. 


\section{B. Pressure Drop}

Figure 5 shows the experimental data obtained for the variation of the coil air pressure drop in $\mathrm{mm} . \mathrm{H} 2 \mathrm{O}$ with the air flow rate in CFM for the two evaporator coils. The coil air pressure drop is greatly affected by the air flow rate. Both coils were equipped with the bell mouth and flow straighteners which contribute to a more fully developed flow before it reaches the coils.

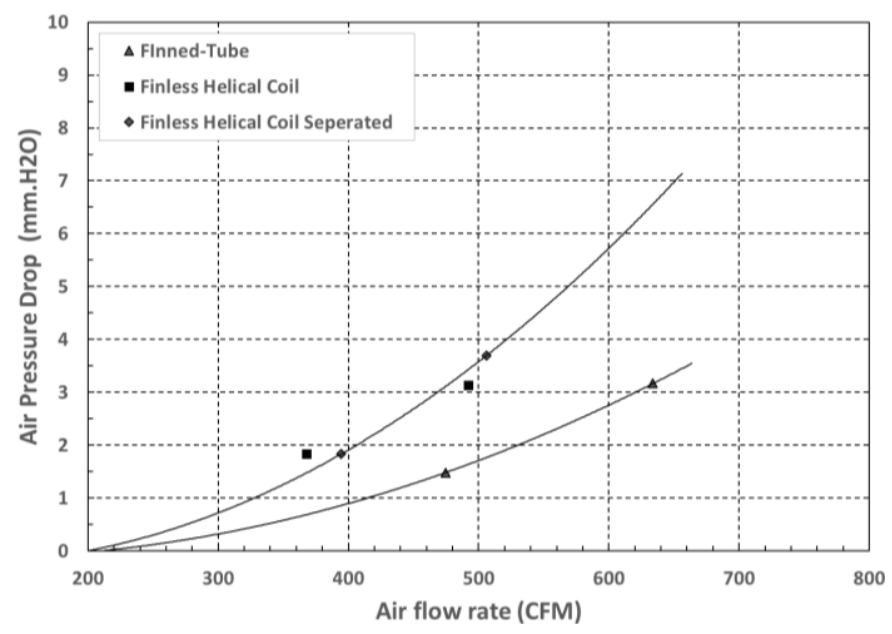

Figure 5 Air pressure drop of finned-tube and helical-spiral evaporative coil for bell-mouth air flow configuration.

The finless helical coils experience a slightly higher pressure drop than that of the plain finned heat exchanger due to the centrifugal force exerted on the air passing through. In addition, separating the double coils had no significant change on the pressure drop, however, a slight difference can be seen due to the imperfect separation of the coils which caused more turbulence at higher flow rates.

In conclusion, the results show a slightly higher pressure drop and a significantly higher cooling capacity per surface area for the new finless coil compared to the finned-tube one and that is mainly due to its higher heat transfer coefficient. As such, by ensuring the right airflow parameters, a helical coil with a smaller surface area can be designed to meet the cooling capacity of a finned coil with a higher surface area, making the design suitable for refrigeration evaporator application.

\section{ACKNOWLEDGMENT}

The authors would like to thank Ontario Center of Excellence (OCE) and the University of Guelph in Canada, for funding the research reported in this paper, through Voucher for Innovation and Productivity I (VIP I) program.

\section{REFERENCES}

[1] V.F. Petrenko, C.R.Sullivan, V. Kozlyuk, F.V. Petremkp, V, Veerasamy. Pulse electo-thermal de-icer (PETD) Cold Regions Science and Technology 65 (2011) 70 .
[2] A. A. Bhuiyan, A.K.M Sadrul Islam. Thermal and hydraulic performance of finned-tube heat exchangers under different flow ranges: A review on modeling and experiment, International Journal of Heat and Mass Transfer 101 (2016) 39-40

[3] F.R. Ameen, J.E. Coney, C.G.W. Sheppard. Experimental stud of warm-air defrosting of heat pump evaporaters Int. J. Refrig., 16 (1) (1993), 13-18

[4] American Society of Heating, Refrigerating and AirConditioning Engineers, Inc. Methods of testing forced circulation air cooling and air heating coils.

[5] T.J. Rennie, V.G.S. Raghavan. Numerical studies of a double-pipe helical heat exchanger. Applied Thermal Engineering 26 (2006) 1266. 